\title{
Imágenes Alteradas: Un ejercicio de interpretación gráfica sobre el sitio de proyecto
}

Altered Images: An exercise of graphic interpretation about the project site

\author{
Alejandro Folga \\ FADU, Uruguay \\ alfotocopias@gmail.com
}

\begin{abstract}
This paper develops an pedagogic activity carried out in an architectural project course. This is an exercise in graphic interpretation that aims to establish a first contact with the project site. The work consists in the students to try different resources of treatment and composition of digital images to express a personal view, previous to the design stage, on the "genius loci" of the project site.
\end{abstract}

Keywords: Enseñanza; Representación; Proyecto; Sitio; Interpretación

\section{Introducción}

En esta ponencia se desarrolla una experiencia pedagógica llevada a cabo en el taller de proyectos Articardi perteneciente a la Facultad de Arquitectura, Diseño y Urbanismo (FADU) de la Universidad de la República (UdelaR) situada en Montevideo, Uruguay. La experiencia consistió en un ejercicio de interpretación gráfica sobre dos sitios de proyecto.

El ejercicio, que hemos denominado Imágenes Alteradas, ha sido realizado en varias oportunidades, aunque aquí nos referiremos específicamente al trabajo desarrollado en el curso de segundo año (Anteproyecto II ${ }^{1}$ durante el segundo semestre de 2016. La temática desarrollada en esa oportunidad se llamó "Paisajes productivos: arquitecturas del vino y del aceite" y consistió en proyectar una bodega o una almazara localizadas en la zona rural del departamento de Maldonado.

Dada la particularidad de los programas arquitectónicos desarrollados, el sitio de implantación se constituye en un aspecto fundamental del proyecto. Por esta condición de fuerte vínculo contextual las "arquitecturas del vino y del aceite" suelen ser especialmente sensibles al sitio en donde se implantan. Algunas se entierran para proteger los delicados productos que elaboran, otras se levantan orgullosas y se constituyen en "mojones" del territorio; en ambos casos se establece una fuerte interacción con el paisaje y la topografía que les da origen.

La actividad pedagógica que explicaremos en esta ponencia tenía por objetivo generar un primer contacto con el sitio, previo a la etapa proyectual, y pretendía la sensibilización de los estudiantes con el particular paisaje en el que se iba a intervenir.
Para ello se diseñó un ejercicio de corta duración que buscaba una aproximación libre y personal; cuyo resultado consiste en plasmar, en un trabajo gráfico de alta carga conceptual, las características dominantes del sitio de proyecto.

En la ponencia se expone: en primer lugar, el marco teórico del ejercicio; luego, la metodología y las estrategias didácticas empleadas; por último, algunos ejemplos de los resultados gráficos obtenidos por los estudiantes.

\section{Marco Teórico}

Empezamos esta sección con una palabra en alemán, zeitgeist, y una expresión en latín, genius loci, que respectivamente designan dos conceptos muy diferentes: el espíritu de la época y el espíritu del lugar.

El término zeitgeist es utilizado para definir el clima cultural de un tiempo histórico determinado. Este concepto fue la principal "bandera" del movimiento moderno, e implicó la adopción de principios universales y de un lenguaje de formas abstractas y genéricas en la arquitectura. Tal vez, la mejor expresión de esta idea globalizadora sea la denominación estilo internacional, con la que en 1932 Henry-Russell Hitchcock y Philip Johnson bautizaron a la vertiente más purista de la arquitectura moderna.

Las posiciones revisionistas de la segunda posguerra tienen como consecuencia profundos cambios en la cultura arquitectónica. En su libro Genius Loci: Hacia una Fenomenología de la Arquitectura Norberg-Schulz (2001) ${ }^{2}$ plantea la necesidad de una revalorización de la idea de lugar. Para ello rescata un término de la mitología romana: genius loci (o espíritu protector de un lugar) y lo utiliza como un concepto fundamental para su teoría de la arquitectura. 


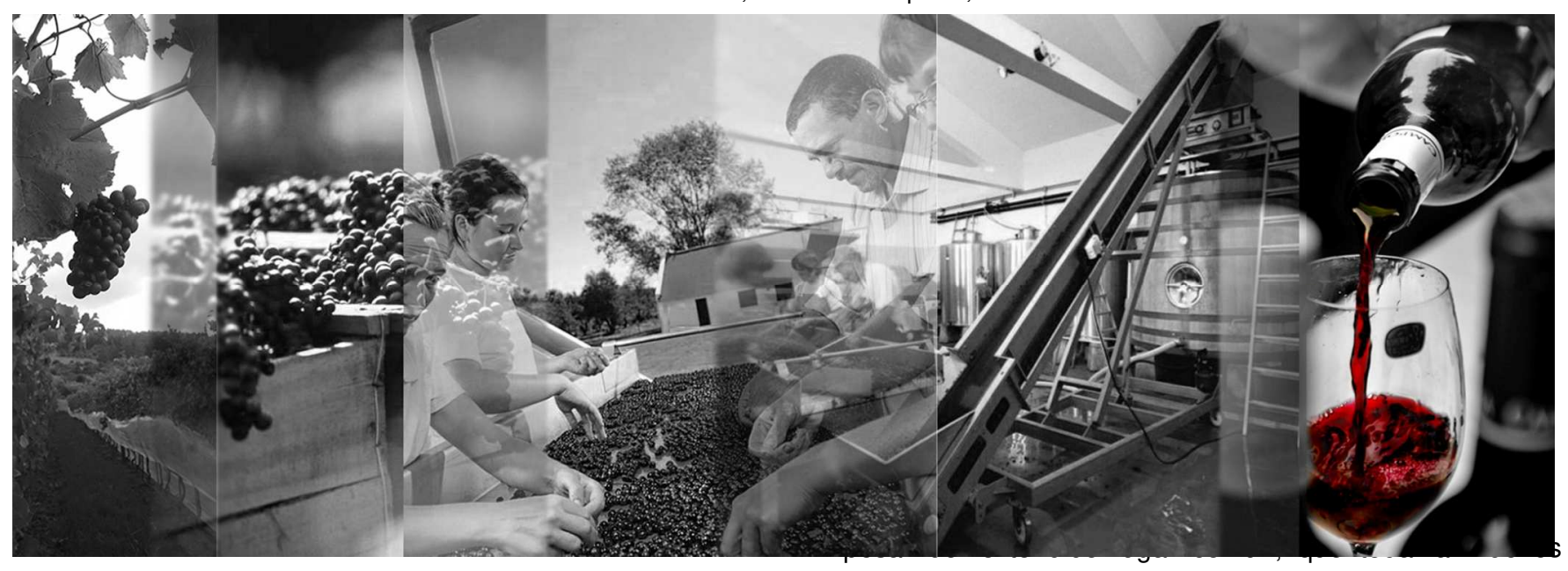

Figura 1: Trabajo realizado por la estudiante Camila Soler.

En el lenguaje común espacio y lugar son conceptos vinculados aunque muy diferentes. El diccionario de la R.A.E. ${ }^{3}$ nos informa que espacio proviene del latín spatium y se refiere a un medio universal, inmaterial e infinito, que contiene a todos los cuerpos físicos. En definitiva, el término designa un vacío de referencia, un mero receptáculo. El mismo diccionario define el término lugar, primero, como "porción de espacio"; luego, como "sitio o paraje"; y, por último, como "ciudad, villa o aldea". En definitiva, siempre se trata de un espacio específico y localizado.

Para la teoría de la arquitectura los términos espacio y lugar también implican una diferencia conceptual, casi podríamos decir que se trata de ideas antagónicas. Javier Maderuelo (2008, p.17) define el lugar como un espacio concreto y diferenciado de otros hasta el punto que puede ser reconocido por sus características físicas y nombrado, de manera que establece una "proyección sentimental" en quien lo usa o lo observa.

En definitiva, reconocer el genius loci consiste en entender el sitio de proyecto no como mero espacio físico disponible, sino como lugar: un espacio que involucra nuestros sentimientos y percepciones, y así puede llegar a quedar fijado en nuestra memoria.

\section{Interpretar el lugar}

La tensión entre lo global y lo local (o entre espacio y lugar) caracterizará los debates durante buena parte del siglo XX. No obstante, más allá de las teorías y los conceptos, los arquitectos más complejos e interesantes siempre consideraron el sitio como un dato fundamental del proyecto. En su libro Mensaje a los Estudiantes de Arquitectura Le Corbusier (1983) ${ }^{4}$ nos dice:

"El sitio es el plato de la composición arquitectónica. Lo comprendí durante un largo viaje que realicé en 1911. [...] Descubri la arquitectura, instalada en su sitio. Y más que eso: la arquitectura expresaba el sitio, —discurso y elocuencia del hombre convertido en señor de los lugares"( $p$.29). promueven $^{5}$, al atribuirle a Le Corbusier la responsabilidad de ser uno de los máximos impulsores de la insensible actitud moderna hacia la ciudad existente; resulta revelador comprobar que el maestro entendía el sitio como un elemento clave en su arquitectura.

En tiempos más recientes el discurso de los arquitectos suele volcarse hacia una categórica reivindicación del sitio como factor principal del proyecto. Así, en un artículo en que el crítico Hernández León (2005) analiza los croquis plasmados en los "cuadernos de viaje" de Álvaro Siza, se nos cuenta que el maestro portugués:

"comienza un proyecto intentando captar lo que un lugar es, puede o desea ser. Así hay que entender su insistencia, casi topográfica, en ese dibujar, previo a toda idea de proyecto, como si el lugar contuviera las respuestas necesarias o pudiera desvelar la clave de esa arquitectura" (p.80)

Para Siza, el hacer croquis del lugar es la principal herramienta proyectual, ya que sus dibujos le permiten entender el sitio de proyecto. Representar lo existente es mucho más que la toma de datos de la realidad para hacer una modificación, es una primera instancia proyectual.

\section{El sitio y paisajismo}

Si para la arquitectura el sitio es un dato fundamental, para el diseño de paisaje se vuelve una premisa ineludible. Desde los orígenes del paisajismo los proyectistas se han preocupado por representar sus propuestas en función de las preexistencias y el contexto ${ }^{6}$.

En su manual sobre dibujo de paisaje Hutchison (2012, p.46) establece que: "En arquitectura, el proyecto de un edificio puede ser novedoso, pero el de un paisaje consiste siempre en convertir un lugar preexistente en algo distinto". Por ello, el autor nos recomienda "entender el contexto" a través de su representación, para desarrollar así una propuesta que acepte lo existente y lo adopte como punto de partida para su transformación. 

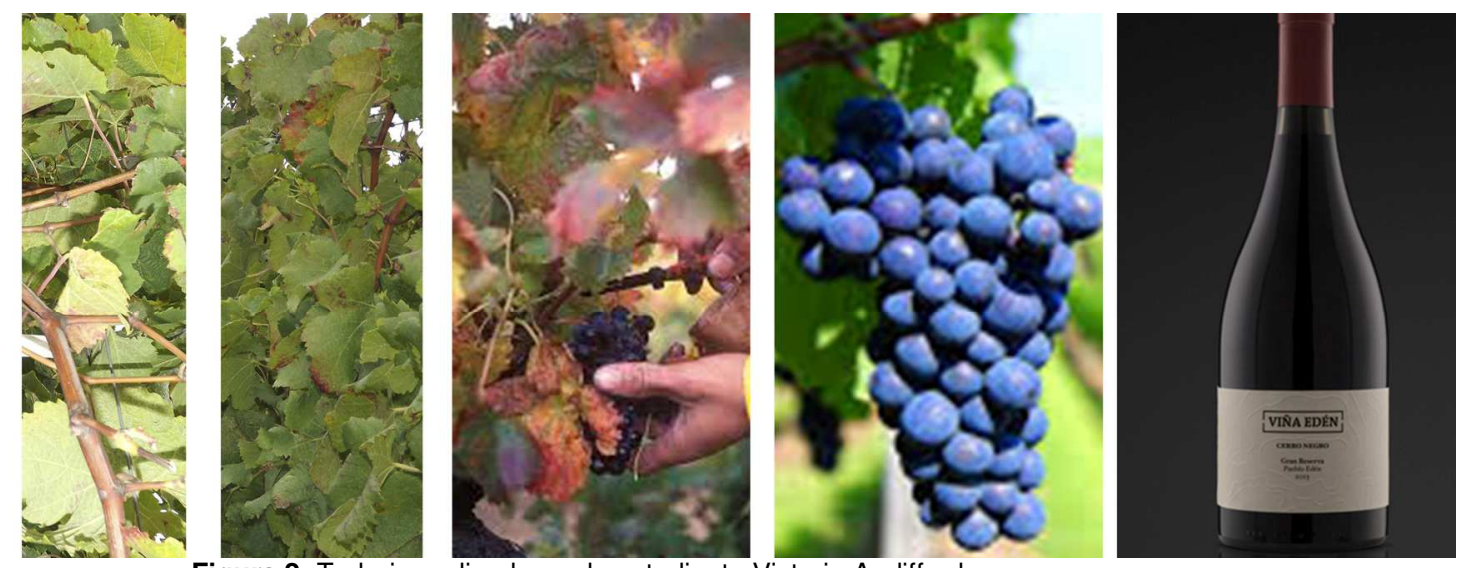

Figura 2: Trabajo realizado por la estudiante Victoria Audiffred.

Por su parte, Besse (2008) reflexiona sobre la relación entre proyecto y paisaje, y se pregunta: “¿Qué es proyectar cuando el espacio no es una página en blanco o una tabla rasa?". Para responder a esta cuestión, analiza la doble acepción que posee el término proyectar:

"Proyectar el paisaje sería a la vez [...] representarlo (proyección) e imaginar lo que podría llegar a ser (proyectación). Esta ambigüedad, o esta circularidad, es constitutiva de la idea misma de proyecto en el pensamiento del paisaje. Pone en relieve las dos dimensiones contenidas en el acto de proyectar: atestiguar, por una parte, y modificar, por otra". (p.168)

Si para proyectar necesitamos conocer lo preexistente, el tomar datos de un lugar y representarlos de manera adecuada constituye un primer acto proyectual.

Waterman y Wall (2013) afirman que durante el proceso de proyecto la representación cumple dos funciones fundamentales: "Primero, a través de la observación y el apunte [...] Luego, a través del proyecto y la transformación" (p.38). Los autores reconocen dos tiempos que se suceden en la actividad del proyectista: el registro de un estado previo y la propuesta de un estado futuro. Más adelante aclaran que la toma de datos y el análisis del sitio deben entenderse como "una fase puramente objetiva en la que se obtiene una imagen estática con el objetivo de comprender el lugar y su contexto" (p.38).

Todas estas ideas nos hablan acerca de que uno de los caminos para activar la percepción en la consideración del sitio pasa por el esfuerzo de interpretarlo gráficamente.

\section{Ejercicio}

En esta sección desarrollaremos algunos puntos relativos al diseño didáctico del ejercicio, y, en particular, detallaremos la implementación del trabajo realizada en el curso de 2016.

\section{Los objetivos}

El ejercicio se propone cumplir con tres objetivos principales. El primero es propender a que el estudiante considere el sitio como un dato fundamental de la propuesta arquitectónica. El segundo es promover la reflexión sobre la representación y el ensayo de herramientas gráficas digitales. El tercero consiste en plasmar, en un trabajo gráfico de alta carga conceptual, las características dominantes, o el genius loci del sitio de proyecto.

\section{El nombre}

Analizado desde el punto de vista gramatical, el adjetivo alteradas que califica al sustantivo imágenes nos da la pauta del tipo de resultado que se pretende conseguir. Si consideramos una lista de sinónimos ${ }^{7}$, el ejercicio trataría de la elaboración de imágenes: "descompuestas, perturbadas, desfiguradas, trastornadas, excitadas, etc.". En definitiva, imágenes que no se encuentran en su "estado natural".

Por otro lado, si nos focalizamos en el significado etimológico del término, encontramos que alterar procede del latín alterāre; y que es una forma verbal de alter (otro). El ejercicio consistiría, entonces, en generar imágenes "otras", es decir, se trata de cuestionar o poner en tensión a la representación convencional para así promover un extañamiento ${ }^{8}$ ante una realidad percibida como común o habitual.

Por lo tanto, el nombre del ejercicio plantea la "obligación" de evitar la obviedad, de trascender la mera reproducción fotográfica del sitio analizado. Para ello se apela al uso intencionado de herramientas digitales y de técnicas gráficas que permitan generar una narrativa visual que resulte alusiva o sugerente de las percepciones e ideas que cada estudiante genera sobre el sitio de proyecto.

\section{Las técnicas}

Como bien señalan Barros y Mandragan (2016), "el tratamiento y manipulación de la imagen digital aporta repertorios extensos de recursos técnicos con alto valor agregado en procesos proyectuales" (p. 194). 


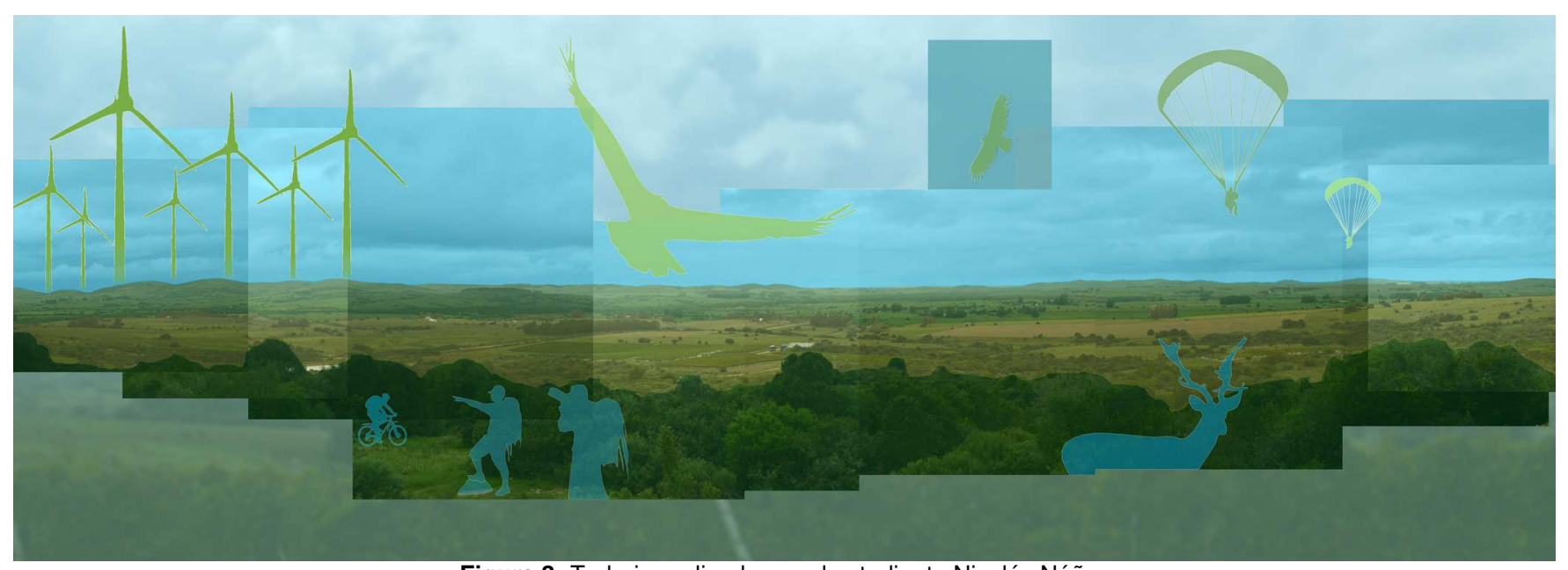

Figura 3: Trabajo realizado por el estudiante Nicolás Núñez.

En ese sentido, la premisa del ejercicio planteaba que los estudiantes ensayen la aplicación de recursos gráficos y expresivos innovadores a través del tratamiento y la manipulación de la imagen digital (escaneos de croquis, imágenes de mapas de bits, dibujo vectorial, incorporación de textos y texturas gráficas, etc.).

Por otro lado, este tipo de ejercicios se convierte en una excelente oportunidad para desarrollar una metodología de trabajo que sea generadora de ideas. Por ello, no se busca solamente producir imágenes representativas del lugar, sino que esas imágenes expresen una determinada intención.

\section{El formato}

El resultado final del ejercicio consiste en que cada estudiante realiza una composición formada por dos láminas de formato DIN A4 apaisado. La definición de este formato responde a dos razones estratégicas.

En primer lugar, cada estudiante debe optar por asociar las láminas en dos posibles disposiciones: una encima de la otra o una junto a la otra. Esta condición producía como resultado dos presentaciones de proporciones drásticamente diferentes: apaisada o vertical, lo que implica una primera elección por parte del estudiante, una toma de partido.

En segundo lugar, el hecho de que las láminas estén moduladas (hoja A4 apaisada) permite conformar una presentación colectiva entre todos los trabajos. El resultado finalmente se expone en el taller y expresa así una visión panorámica del grupo, que se manifiesta en un tapiz gráfico donde se reúne la multiplicidad de miradas y lecturas producidas sobre un mismo sitio.

\section{Metodología}

En nuestro curso algunos trabajos se realizan en forma grupal (análisis de ejemplos y ejercicios proyectuales de corta duración) mientras que otros son de carácter individual, como el caso que se presenta en esta ponencia. La opción por el trabajo individual busca generar un involucramiento más personal y perceptivo con el sitio, ya que cada estudiante produce su propia síntesis gráfica.
Dado que se trata de una experiencia de corta duración (dos semanas) resulta fundamental la elaboración de un diseño pedagógico que sea eficiente para el escaso tiempo disponible. Atendiendo a esta cuestión, el trabajo se realizó bajo la modalidad didáctica de taller y se desarrolló en cuatro etapas sucesivas: (1) previa a la visita, (2) trabajo in situ, (3) post visita y (4) entrega y evaluación.

\section{Etapa 1- previa a la visita}

En una clase, previa a la visita del sitio, el equipo docente realiza la presentación del ejercicio. Esta instancia "teórica" es fundamental para explicar los objetivos y la dinámica del trabajo "práctico", a la vez que permite brindar, a los estudiantes, un amplio repertorio de recursos gráficos y conceptuales para llevar a cabo la "alteración" de las imágenes. En esa clase se insiste en la importancia de tener un conocimiento directo del sitio, un contacto vivencial, no mediatizado. Por otro lado, se alienta a utilizar diferentes medios gráficos: fotografías, dibujos, toma de datos dimensionales, registros escritos, etc.

\section{Etapa 2 - in situ}

En la segunda etapa los estudiantes deben llevar a cabo el registro del sitio de proyecto. Para ello el equipo docente organiza una visita junto con los estudiantes. Dado que el tiempo de la visita es muy acotado, se define un intervalo temporal en el que los estudiantes recorren el lugar libremente, de manera que puedan obtener un contacto más personal ${ }^{9}$ con el sitio.

\section{Etapa 3 - post visita}

Luego de procesar la información obtenida durante la visita se comienzan a desarrollar las primeras ideas gráficas. Esta etapa implica que los estudiantes presenten sus avances al equipo docente. Para ello se realizan un par de instancias de corrección. La primera es colectiva, se presenta en paneles y se hace en la modalidad de crítica indirecta ${ }^{10}$; mientras que la segunda es individual, se presenta en mesas y se realizan sugerencias para el ajuste de cada propuesta. Para asegurarnos de que todos los trabajos hayan sido vistos por el equipo docente, exigimos que cada estudiante tenga, al menos, una corrección de su propuesta antes de la entrega final. 


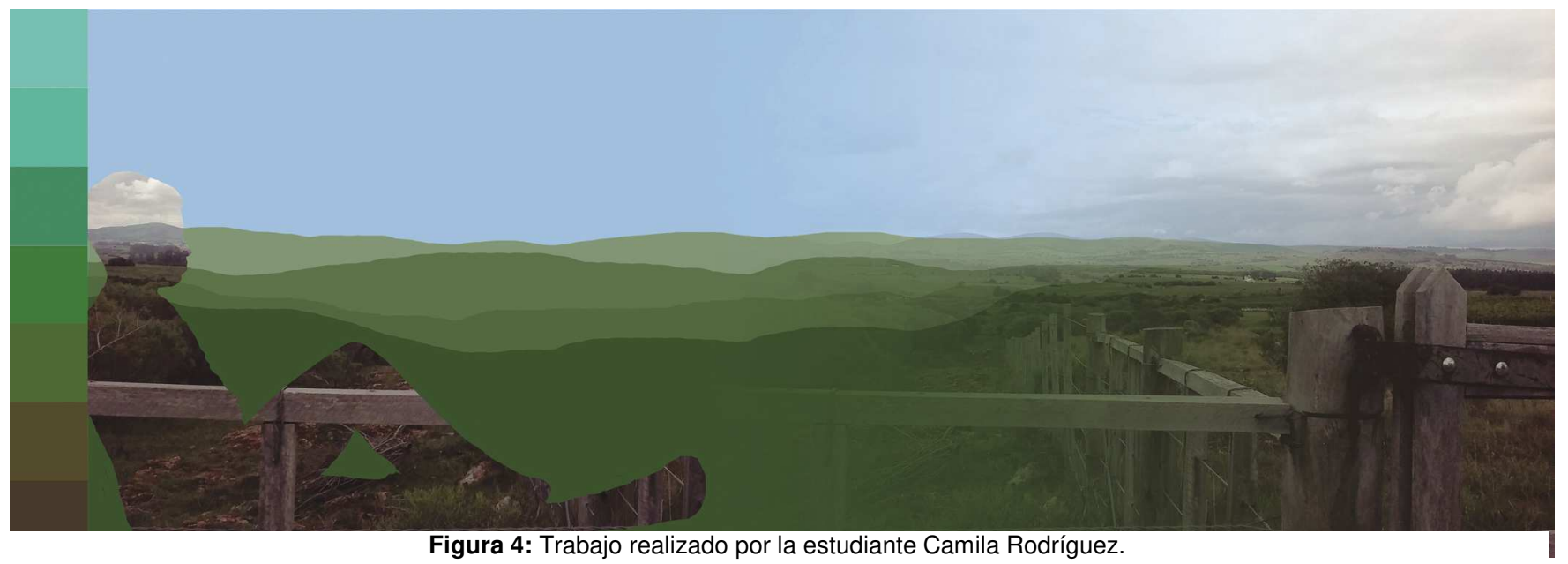

\section{Etapa 4 - entrega y evaluación}

La actividad culmina con una presentación de los trabajos y la realización de un panel colectivo con las láminas de todos los estudiantes, de manera que todos puedan observar las entregas de sus compañeros. Este panel colectivo funciona como un "testimonio gráfico" de las primeras impresiones que el sitio produjo sobre los proyectistas.

El equipo docente cierra el ejercicio con una clase de evaluación realizada mediante una presentación audiovisual. En esta instancia se comparan y categorizan los resultados obtenidos, se analizan los vínculos entre diferentes propuestas y se establecen valoraciones generales de todo el trabajo realizado y de las diferentes estrategias empleadas por los estudiantes.

\section{Conclusiones}

Considerado desde el punto de vista de la enseñanza de la representación, este ejercicio consigue que los estudiantes ensayen diferentes formatos y modalidades expresivas. Vale la pena destacar algunas de las estrategias empleadas en los ejemplos aquí presentados: el uso selectivo del color como recurso de énfasis visual (Figura 1), la construcción de secuencias y narrativas visuales (Figuras 1, 2 y 3), la comparación o contraposición de dos situaciones diferentes (Figura 5).

Desde el punto de vista del proyecto también surgen algunas estrategias que podemos analizar a través de los ejemplos seleccionados. Es interesante cómo, en algunos casos, el imaginario de los estudiantes sobre la producción agrícola se traslada a la lámina de forma casi literal. Esto se ilustra, por ejemplo, en las secuencias de cultivo, procesamiento y almacenamiento vitivinícola (Figuras 1 y 2). En otros casos, la valoración del paisaje y los puntos de vista que este permite actúan como factor preponderante, lo que conlleva el desarrollo de una posible explotación turística del sitio. Esto se sugiere a través de deportes relacionados con el paisaje 0 actividades de descanso contemplativo (Figuras 3 y 4 ).
Como resumen, este ejercicio posibilita que los estudiantes puedan:

- Registrar los aspectos fundamentales del sitio.

- Plasmar una mirada personal y sensible.

- Expresar conceptualmente lo analizado.

- Generar una narración gráfica intencionada.

- Revelar, a través de una lectura creativa, las potencialidades del sitio como tema de proyecto.

Aunque esta ponencia se ilustra solamente con algunos trabajos producidos en el curso de Anteproyecto II del año 2016, es de rigor aclarar que en las diferentes oportunidades que hemos ensayado este ejercicio hemos obtenido expresiones de gran interés gráfico y conceptual.

En el primer semestre de 2017 hemos implementado este ejercicio en un curso de proyecto que pertenece al ciclo inicial (Unidad curricular Proyecto y Representación I y II). A pesar que se trata de estudiantes que tienen dos años menos de trayectoria en la FADU, hemos aplicado prácticamente las mismas pautas que en el ejercicio aquí presentado. Los resultados obtenidos han sido muy satisfactorios, en relación con el nivel gráfico alcanzado por el mismo grupo en otros trabajos que fueron realizados durante el curso.

\section{Discusión}

Consideramos que este tipo de ejercicios "obliga" (en el mejor sentido de la palabra) a que el estudiante mire el sitio con atención. Esa mirada, atenta y selectiva, es una mirada intencionada, una mirada que cuestiona e interroga ${ }^{11}$. En definitiva, se trata de una primera aproximación al proyecto, pero no desde la propuesta sino desde una lectura creativa de lo existente. Como proyectistas nuestra mirada siempre se permea de intenciones y "proyecta" sobre el sitio nuestro imaginario acerca del programa, de la implantación, de las vistas. En ese sentido, y parafraseando a Alvaro Siza, no vemos al sitio solamente como lo que es, sino como lo que puede o desea ser. 


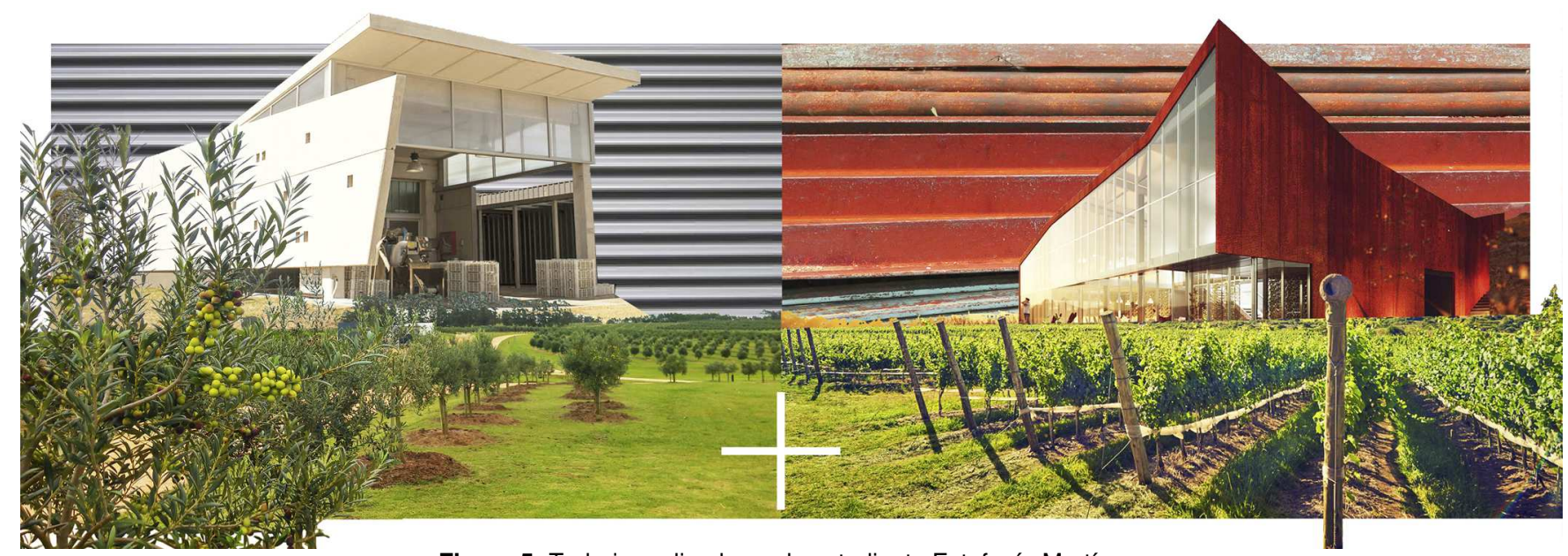

Figura 5: Trabajo realizado por la estudiante Estefanía Martínez

\section{Agradecimientos}

En primer lugar debo agradecer a todos los docentes del curso Anteproyecto II del Taller Articardi, por haber compartido conmigo esta experiencia y por los muchos aportes que realizaron para la mejora conceptual y pedagógica de este trabajo. En segundo lugar debo agradecer a todos los estudiantes que han participado del ejercicio, porque ellos son quienes dan sentido a esta experiencia y porque con su entusiasmo y con sus ideas otorgan las mayores satisfacciones por nuestra labor docente.

\section{Notas}

1 En el año 2016 el curso de Anteproyecto II de taller Articardi estuvo integrado por los siguientes docentes: Alejandro Folga (coordinador), Mario Blechmann, Gustavo Vila, Natalia Botta, Germán Aguirre, Paola Florio, Virginia García, Alberto de Austria, Rodrigo Muñoz, Marcelo Pacheco y Karen Filippini.

2 El título original del libro es Genius Loci: Towards a Phenomenology of Architecture, y fue publicado por primera vez en 1980.

3 El diccionario de la RAE (consultado en la web) contiene un total de 14 definiciones sobre la palabra espacio, de las cuales la primera es la que más nos interesa: "Extensión que contiene toda la materia existente". Para la palabra "lugar" se dan nueve definiciones diferentes.

4 El título original del libro es Entretien avec les étudiants des Ecoles d'Architecture y fue publicado por primera vez en 1957.

5 Esta falacia ya ha sido señalada por diversos autores. Por ejemplo, el crítico Carlos Marti Aris (2011) expresa que "aún sigue siendo útil a muchos la idea de cargar a Le Corbusier la culpa de los mayores abusos cometidos en nombre de la ciudad contemporánea, sin concederle a cambio el mérito de ninguno de sus beneficios" (p. 102).
6 Un ejemplo notable es el de Humphrey Repton y sus acuarelas que presentan el "antes y después".

7 El diccionario de la RAE nos ofrece cuatro diferentes definiciones para el verbo alterar: "1. tr. Cambiar la esencia o forma de algo. 2. tr. Estropear, dañar, descomponer. 3. tr. Perturbar, trastornar, inquietar. 4. tr. Enojar, excitar." Está claro que en este ejercicio nos interesan más la primera y la tercera definición.

8 La vasta Wikipedia nos informa que: "Con el nombre de extrañamiento o desfamiliarización se indica a todas aquellas intervenciones sobre las formas artísticas que tienen como objetivo el hacerlas extrañas a su misma naturaleza, creando de este modo en los destinatarios un sentimiento de alienación".

9 Es importante aclarar que en algunos casos esta visita al sitio debe desdoblarse en dos trabajos paralelos: el ejercicio de percepción personal y la toma de datos más "objetivos" (relevamientos dimensionales y fotográficos) que después serán necesarios en la etapa de proyecto.

10 Sobre la crítica indirecta véase: Velázquez, R., Perdomo, A. (1992). La Enseñanza en los Talleres de Anteproyecto, Método didáctico y evaluación de resultados en una enseñanza masificada. Montevideo: Facultad de Arquitectura.

11 Vale la pena recordar una conocida frase de Le Corbusier, en que se hace referencia a esa relación con lo proyectual que tiene la mirada: "La clave es mirar. Mirar, observar, ver, imaginar, inventar, crear" (como se cita en de Lapuerta, 1997, p. 54).

\section{Referencias}

BARROS, DIANA; MANDAGARAN, MARÍA (2016) "Diseño especulativo, co-creación y Casa del Puente. Un caso de prácticas didácticas en entorno de post-digitales en la carrera de Arquitectura", p. 194-200. En: XX Congreso de la Sociedad Iberoamericana de Gráfica Digital, 2016. 
BESSE, J. (2008). "Las cinco puertas del paisaje". En: Paisaje y pensamiento (145-172). Madrid: Abada.

DE LAPUERTA, J. M. (1997). El croquis, proyecto y arquitectura. Madrid: Celeste ediciones.

HUTCHISON, E. (2012). El dibujo en el proyecto del paisaje. Barcelona: Gustavo Gili.

LE CORBUSIER (1983) Mensaje a los estudiantes de Arquitectura. Buenos Aires: Infinito.

MADERUELO, J.(2008). La idea de espacio en la arquitectura y el arte contemporáneos, 1960-1989. Madrid: Akal.
MARTí ARÍS, CARLOS. (2011). Cabos sueltos. Madrid: Sánchez Lampreave.

NORBERG-SCHULZ, CH. (2001) Genius loci. Barcelona: Editorial. G.Gili.

VELÁZQUEZ, R., PERDOMO, A. (1992). La Enseñanza en los Talleres de Anteproyecto, Método didáctico y evaluación de resultados en una enseñanza masificada.

WATERMAN,T.; WALL, E. (2013, agosto). "Un diálogo con el paisaje: proyecto, representación y proceso". Urban, 05, pp. 37-48. 